Human Mutation

WILEY

\title{
Identification and functional analyses of CBS alleles in Spanish and Argentinian homocystinuric patients
}

\begin{tabular}{|c|c|}
\hline Journal: & Human Mutation \\
\hline Manuscript ID: & humu-2010-0637.R1 \\
\hline Wiley - Manuscript type: & Research Article \\
\hline $\begin{array}{r}\text { Date Submitted by the } \\
\text { Author: }\end{array}$ & 31-Mar-2011 \\
\hline Complete List of Authors: & $\begin{array}{l}\text { Cozar, Monica; Universitat de Barcelona, Departament de Genetica; } \\
\text { CIBERER; IBUB } \\
\text { Urreizti, Roser; Universitat de Barcelona, Departament de Genetica; } \\
\text { CIBERER; IBUB } \\
\text { VILARINHO, Laura; Medical Genetics Institute, Clinical Biology } \\
\text { Grosso, Carola; Universidad Nacional de Córdoba Hospital de Niños, } \\
\text { Centro de Estudio de las Metabolopatías Congénitas, CEMECO, } \\
\text { Facultad de Ciencias Médicas } \\
\text { Dodelson de Kremer, Raquel; Universidad Nacional de Córdoba } \\
\text { Hospital de Niños, Centro de Estudio de las Metabolopatías } \\
\text { Congénitas, CEMECO, Facultad de Ciencias Médicas } \\
\text { Asteggiano, Carla; Children's Hospital of Santisima Trinidad, } \\
\text { CEMECO } \\
\text { Dalmau, Jaime; Hospital Infantil La Fe, Division of Metabolism, } \\
\text { Garcia, Ana; Hospital Infantil La Fe, Division of Metabolism, } \\
\text { Vilaseca, María; Hospital Sant Joan de Déu, Bioquímica } \\
\text { Grinberg, Daniel; Universitat de Barcelona, Departament de } \\
\text { Genetica; CIBERER; IBUB } \\
\text { Balcells, Susana; Universitat de Barcelona, Departament de } \\
\text { Genetica; CIBERER; IBUB }\end{array}$ \\
\hline Key Words: & $\begin{array}{l}\text { CBS mutations, homocystinuria, Southern blot, mini-gene, } \\
\text { heterologous expression, enzyme activity }\end{array}$ \\
\hline
\end{tabular}

\section{SCHOLARONE $^{\text {TM }}$ Manuscripts}




\section{Identification And Functional Analyses of CBS Alleles In Spanish And}

\section{Argentinian Homocystinuric Patients}

Mónica Cozar, ${ }^{1 *}$ Roser Urreizti, ${ }^{* *}$ Laura Vilarinho, ${ }^{2}$ Carola Grosso, ${ }^{3}$ Raquel Dodelson de Kremer, ${ }^{3}$ Carla G. Asteggiano, ${ }^{3}$ Jaime Dalmau, ${ }^{4}$ Ana María García, ${ }^{4}$ María Antonia Vilaseca, 5 Daniel Grinberg, ${ }^{1 *}$ and Susana Balcells ${ }^{1 * \#}$

${ }^{1}$ Departament de Genètica, Universitat de Barcelona, IBUB, Centro de Investigación Biomédica en Red de Enfermedades Raras (CIBERER), ISCIII, Barcelona, Spain ${ }^{2}$ Instituto de Genética Médica Jacinto Magalhaes, Porto, Portugal

3 Centro de Estudio de las Metabolopatías Congénitas (CEMECO), Facultad de Ciencias Médicas, Universidad Nacional de Córdoba, Hospital de Niños de la Santísima Trinidad, Córdoba, Argentina.

${ }^{4}$ Unidad de Nutrición y Metabolopatías. Hospital Infantil La Fe, Valencia, Spain. ${ }^{5}$ Servei de Bioquímica. Hospital Sant Joan de Déu, Barcelona, Spain.

* Equal contributors.

\# Correspondence to: Dr. Susana Balcells, Departament de Genètica, Facultat de Biologia, Universitat de Barcelona, Av. Diagonal 645, E-08028, Barcelona, Spain. Email: $\underline{\text { sbalcells@ub.edu }}$

Tel.: +34934035418

Fax: +34934034420 


\begin{abstract}
Homocystinuria due to CBS deficiency (MIM\#236200) is a rare autosomal recessive disorder characterized by elevated plasma levels of homocysteine (Hcy) and methionine (Met). Here we present the analysis of 22 unrelated patients of different geographical origins, mainly Spanish and Argentinian. Twenty-two different mutations were found, ten of which were novel. Five new mutations were missense and five were deletions of different sizes, including a 794bp deletion (c.532-37_736+438del794) detected by Southern blot analysis. To assess the pathogenicity of these mutations, seven were expressed heterologously in E. coli and their enzyme activities were assayed in vitro, in the absence and presence of the CBS activators PLP and SAM. The presence of the mutant proteins was confirmed by Western-blotting. Mutations p.M173del, p.I278S, p.D281N and p.D321V showed null activity in all conditions tested, while mutations p.49L, p.P200L and p.A446S retained different degrees of activity and response to stimulation. Finally, a minigene strategy allowed us to demonstrate the pathogenicity of an 8-bp intronic deletion, which led to the skipping of exon 6. In general, frameshifting deletions correlated with a more severe phenotype, consistent with the concept that missense mutations may recover enzymatic activity under certain conditions.
\end{abstract}

KEY WORDS: CBS mutations; homocystinuria; Southern blot; mini-gene; heterologous expression; enzyme activity 


\section{Introduction}

Homocysteine (Hcy) is a sulfur-containing amino acid that occupies a major regulatory branch point in methionine metabolism. Homocysteine may be either remethylated to methionine or catabolized to form cysteine through the transsulfuration pathway. The first step of transsulfuration involves the condensation of homocysteine with serine to form cystathionine, a reaction catalyzed by the enzyme cystathionine $\beta$-synthase (CBS; EC 4.2.1.22).

Mutations in the CBS gene (MIM\# 613381) cause classical homocystinuria (Hcu, MIM\# 236200), an autosomal recessive disease characterized by severe hyperhomocysteinemia and homocystinuria, decreased plasma levels of cysteine and, often, hypermethioninemia. At the clinical level, classical homocystinuria mainly affects the eye, the skeleton, the vascular system and the central nervous system (CNS). Symptoms usually include ectopia lentis, osteoporosis, scoliosis, Marfanoid features, premature arteriosclerosis, thromboembolism and mental retardation (Mudd, et al., 1985). Age of onset and disease severity are highly variable, ranging from dramatically affected children to asymptomatic adults (Magner, et al., 2011; Skovby, et al., 2010; Walter, et al., 1998; Yap and Naughten, 1998). Treatments that lower tHcy, such as B-vitamins, dietary methionine restriction, and betaine supplementation, can significantly reduce the incidence of vascular events (the main cause of death in these patients) and improve the neurological problems (Wilcken and Wilcken, 1997; Yap, et al., 2001; Yap and Naughten, 1998).

Homocystinuria is a rare disease with variable incidence. While the worldwide incidence is estimated as 1/344000 born alive (Mudd, et al., 1995), in Qatar it is 1/3124 (El-Said, et al., 2006) and in Japan 1/800 000 (Mudd, et al., 1995). In Northern Europe the incidence may be of $1 / 20500$ to $1 / 6400$, as estimated from the high 
number of p.I278T mutation carriers found in some populations (Gaustadnes, et al., 1999; Refsum, et al., 2004).

To date, more than 150 different CBS mutations have been found worldwide, some of them common. Mutation p.I278T is considered panethnic and is particularly frequent in Northern Europe (Janosik, et al., 2001b; Kraus, et al., 1999; Moat, et al., 2004). In Ireland, the p.G307S mutation accounts for $71 \%$ of the mutant alleles (Gallagher, et al., 1995), and in the Iberian Peninsula and Colombia, mutation p.T191M represents between $40 \%$ and $75 \%$ (Urreizti, et al., 2006a) of the mutant alleles.

A truncated form of the human CBS enzyme lacking the C-terminal regulatory domain has been crystallized (Janosik, et al., 2001a; Meier, et al., 2001) and structurally characterized (Banerjee and Zou, 2005; Kabil, et al., 2001; Kery, et al., 1999; Meier, et al., 2001; Taoka, et al., 2002). The active form of this cytoplasmic enzyme is a homotetramer of four $63-\mathrm{KDa}$ subunits. Each subunit combines one heme group and one pyridoxal phosphate (PLP), the latter acting as a cofactor in the reaction. In addition, each subunit binds the allosteric activator S-AdenosilMethionine (S-AdoMet or SAM), an intermediate in the methionine cycle. Heterologous expression in E. coli has been widely used to test the functionality of the CBS mutant alleles independently from the patient's genetic background (de Franchis, et al., 1994; Katsushima, et al., 2006; Maclean, et al., 2002). It has been proven to be a useful tool since the E. coli-expressed human CBS is indistinguishable from that obtained from cultured fibroblasts (Bukovska, et al., 1994; Kozich and Kraus, 1992). In addition, in vitro, its relative activity in response to PLP and SAM is comparable to that of the enzyme obtained from human tissues (Bukovska, et al., 1994; Kozich and Kraus, 1992). 
This study updates the CBS mutation spectrum of the homocystinuric patients from the Iberian Peninsula by presenting the analysis of 16 new cases. It also includes one Norwegian, one Indian and four Argentinian patients. In this cohort of 22 cases, 22 mutations were found, ten of which were novel. The new mutations include a deletion of 794 bp (c.532-37_736+438del794) detected by Southern blot analysis and an intronic deletion that leads to the skipping of exon 6 , which was characterized using a minigene strategy. The pathogenic role of seven of the changes was assessed by heterologous expression of these mutant proteins, and their stability and activity were analyzed.

\section{Materials And Methods}

\section{Patients}

Twenty-six patients with classical homocystinuria from 22 unrelated pedigrees were involved in this study. Patients were initially diagnosed by their physicians on the basis of clinical manifestations suggestive of homozygous CBS deficiency. Biochemically, these patients presented with a combination of severe hyperhomocysteinemia (typically above $150 \mu \mathrm{mol} / 1$ ), and hypermethioninemia (typically above $40 \mu \mathrm{mol} / \mathrm{l}$ ). Thirteen Spanish, three Portuguese, one Norwegian, one Indian and four Argentinian patients were included in the study. Our research was conducted in accordance with the tenets of the Declaration of Helsinki. The nature and possible consequences of the study were first explained to all patients and/or their parents, before their informed consent for inclusion in the research project was obtained. 


\section{PCR amplification and DNA sequencing}

Genomic DNA was prepared from peripheral blood leukocytes, using a Wizard Genomic DNA Purification Kit (Promega, Madison, WI, USA).

All 16 CBS coding exons (including exon 15) and their intronic flanking regions, were amplified by PCR and sequenced as described previously (Urreizti, et al., 2006a) with some modifications. Briefly, PCR reactions were performed on a final volume of $50 \mu \mathrm{l}$ with $50 \mathrm{ng}$ gDNA, $0.2 \mathrm{mM}$ of each dNTP, $0.4 \mathrm{mM}$ of each primer, 1.5-2.5 $\mathrm{mM} \mathrm{MgCl}_{2}$ and 1.25 $\mathrm{U}_{\text {of }} \mathrm{GoTaq}^{\circledR}$ Flexi DNA Polymerase (Promega, Madison, WI, USA). All mutations detected were confirmed by restriction analysis of the PCR products with the appropriate restriction enzyme, and the presence of all new mutations was assessed in 100 control chromosomes from Spanish anonymous donors. Primer sequences and PCR conditions have been described previously (Urreizti, et al., 2006a). MTHFR c.677C>T (rs1801133) was analyzed in all patients as described in Frosst et al. (Frosst, et al., 1995).

To characterize the deletion found in patient 87 , genomic DNAs of the patient and her parents were PCR-amplified using primers $4 \mathrm{~F}$ and $7 \mathrm{R}$ as described above with the addition of a final concentration of $5 \%$ DMSO. The PCR fragments were purified and sequenced.

For naming the mutations the following reference sequences were used: Genomic, GenBank NG_008938.1; cDNA, ENST00000352178. Nucleotide numbering reflects cDNA numbering with +1 corresponding to the A of the ATG translation initiation codon in the reference sequence, according to journal guidelines (www.hgvs.org/mutnomen). The initiation codon is codon 1. 


\section{Southern blot}

A Southern blot to analyze a 36-kb fragment of the CBS genomic region (Fig. 1), between two DrdI sites, encompassing all 23 exons, plus $6 \mathrm{~kb}$ of the $5^{\prime}$ flanking region and $11.5 \mathrm{~kb}$ of the $3^{\prime}$ region, was performed as follows: $10 \mu \mathrm{g}$ of patient and control gDNA were double digested by DrdI and AflII (NEBiolabs, Ipswich, MA, USA), electrophoresed on a $0.9 \%$ agarose gel, blotted onto Amersham Hybond ${ }^{\mathrm{TM}}-\mathrm{N}+(\mathrm{GE}$ Healthcare, Waukesha, WI, USA) membrane using standard protocols, and fixed by UV crosslinking. The DrdI/AflII double digestion of the $36 \mathrm{~kb}$ yields, in a wild-type setting, four fragments of around $15 \mathrm{~kb}, 10 \mathrm{~kb}, 8 \mathrm{~kb}$ and $3 \mathrm{~kb}$, respectively (Fig. 1A).

\section{Probe design, preparation and hybridization}

Four probes were designed by selecting one unique sequence of approximately $600 \mathrm{bp}$ within each restriction fragment. The sequences were aligned to the whole genome by BLAST, to confirm their specificity. These four sequences were PCRamplified from total genomic DNA (as described above), cloned into pUC19 vector (Fermentas, Burlington, ON, Canada) and sequenced. Probes were obtained from the clones by using digoxigenin-dUTP and the "PCR DIG Probe Synthesis Kit" (Roche, Mannheim, Germany), according to the manufacturer's instructions. Primer sequences for the probes are available on request. Labelled probes were subsequently purified using IllustraTM GFX ${ }^{\mathrm{TM}}$ PCR DNA and a Gel Band Purification Kit (GE Healthcare, Waukesha, WI, USA).

All subsequent steps of the Southern protocol (prehybridization, hybridization and developing of the filters) were performed using reagents (Dig Easy Hyb) and protocols (Dig Application Manual) from Roche (Mannheim, Germany). 


\section{Site-directed mutagenesis, heterologous expression and in vitro enzyme activity assays of the $C B S$ mutations}

All CBS mutant constructs were derived from the wild-type CBS expression plasmid pHCS3 (Kozich and Kraus, 1992), a gift from the authors of that study. Each mutation was introduced into the wild-type expression plasmid using a Quik Change II XL TM Site-Directed Mutagenesis Kit (Stratagene Cloning Systems, La Jolla, CA, USA) and expressed in XL-Gold E. coli cells as described in Urreizti et al. (Urreizti, et al., 2006b). Expression of pHCS3 was used as a positive control, and that of the empty vector pKK388.1 was included as a negative control. Protein extracts were obtained and CBS activity was measured as described in Kraus (Kraus, 1987) with some modifications (Urreizti, et al., 2006b).

\section{CBS protein analysis}

To assess the presence and relative amount of wild-type and mutant CBS proteins, Western blot analysis of the soluble fraction of the crude cell lysates was performed under denaturing conditions as described in Janosik et al. (Janosik, et al., 2001b), with some modifications (Urreizti, et al., 2006b).

\section{Minigene construction and splicing assay}

Genomic DNA from patient 68a (heterozygote for mutation c.667-14_-7del8) was amplified using $C B S$ primers $4 \mathrm{~F}$ and $6 \mathrm{R}$ to obtain a fragment of 626 or $618 \mathrm{bp}$ (from the last $29 \mathrm{bp}$ of intron 3 to the first $103 \mathrm{bp}$ of intron 6). This PCR product, containing both wild-type and mutant alleles, was purified using IllustraTM GFXTM 
PCR DNA and a Gel Band Purification Kit (GE Healthcare, Waukesha, WI, USA) and cloned into the pGLB1 vector (Diaz-Font, et al., 2005). Plasmid pGLB1 is based on a pcDNA3.1 vector and contains exons 7, 8, and 9 and introns 7 and 8 of the GLB1 gene, where intron 7 contains a PmeI restriction site, which was used to clone the CBS fragment. The resulting plasmids, named pGLB1-CBS_wt and pGLB1-CBS_mut, were confirmed by sequencing.

The splicing assay was performed by transfecting $1 \mu \mathrm{g}$ of each minigene plasmid with $5 \mu$ l of Lipofectamine 2000 Reagent (Life Technologies, Basel, Switzerland) into 90\% confluent HeLa cells. Total RNAs were isolated $24 \mathrm{~h}$ after transfection using the QIAshredder and the RNeasy Mini Kit (QIAGEN, Hilden, Germany). RNA concentration was determined spectrophotometrically, integrity was verified by gel electrophoresis and RNA quality was assessed by OD 260/230 and $260 / 280$ ratios.

Two $\mu \mathrm{g}$ of each RNA was reverse-transcribed in a final volume of $20 \mu \mathrm{l}$ using a High Capacity cDNA Reverse Transcription Kit with RNase Inhibitor (Applied Biosystems, Foster City, CA, USA) according to the manufacturer's instructions.

PCR amplification of each cDNA product was performed using primers T7 and SP6 as previously described (Diaz-Font, et al., 2005; Santamaria, et al., 2008). The PCR products were electrophoresed and each band of interest was purified and analyzed by sequencing.

\section{Results}

Screening for CBS mutations 
Twenty-two different mutations (Table 1), ten of them novel, were found in 22 unrelated patients of different geographical origin (Table 2). Forty-two mutant alleles were identified through sequencing of coding exons and flanking intronic regions, while an additional mutant allele was discovered by Southern blot analysis (see below). Only one allele remained unidentified. Five of the new mutations were missense while five were deletions.

After sequencing the complete CBS coding sequence, only mutation c.1566delG was found in heterozygosis in patient 87 , which she inherited from her father. A Southern blot analysis of this patient and her mother, hybridized with a set of four probes covering the entire $C B S$ genomic region (Fig. 1A), revealed the same pattern of bands observed in control samples but the relative intensities of fragments 2, 3 and 4 were altered (Fig. 1B). Hybridization of the same membrane separately with each individual probe revealed an additional band of nearly $10 \mathrm{~kb}$ detected by probes $\mathrm{B}$ and C (Fig. 1C). This result was consistent with a deletion removing the DrdI site present in intron 5. To test this hypothesis, a PCR amplification from intron 3 to intron 7 was performed. As shown in Fig. 1D, a new band of $1176 \mathrm{bp}$ was observed in the samples of the patient and her mother. Sequencing revealed a 796-bp deletion (c.532-37_736+438del794), which spans from the last 37 bp of intron 4 to the first 438 bp of intron 6 (Fig. 1E). This deletion causes a frameshift starting from a valine to glycine substitution at position 178 and leading to a stop codon at residue 201 (p.V178GfsX23).

\section{Analyses of pathogenicity of mutant CBS enzymes}

None of the new mutations found was present in 100 control chromosomes, ruling out the possibility of common polymorphisms. 
We assessed the pathogenicity of all five new missense mutations and of the novel in-frame deletion p.M173del using an E. coli heterologous expression system followed by Western blot and in vitro enzyme activity analysis (Fig. 2). Mutation p.P49L, previously described by de Franchis et al. (de Franchis, et al., 1998) was also analyzed.

All the proteins from the mutant alleles were found in amounts similar to those of the wild type (Fig. 2, upper panel). The activity of these mutant enzymes was assayed in vitro, either in the presence or absence of the cofactor PLP, or in the joint presence of PLP and SAM (Fig. 2, lower panel). As previously described (Kluijtmans, et al., 1996; Maclean, et al., 2002), we found that the wild-type CBS activity was strongly stimulated by both PLP and the combination of PLP and SAM. Mutations p.M173del, p.I278S, p.D281N and p.D321V showed null activity, either in the absence or presence of the activators. In contrast, mutations p.49L, p.P200L and p.A446S retained different amounts of activity and also the ability to be stimulated.

In particular, mutation p.P49L displayed null activity in the absence of any of the activators, retained $71 \%$ of the wild-type activity in the presence of PLP and showed reduced activation by SAM. In contrast, in the absence of any of the activators, mutation p.P200L displayed around a third of the activity of the wild type ( $15 \%$ versus $43 \%$ ) and retained the ability to be induced by PLP and SAM. SAM stimulation was 2-fold, comparable to that of the wild type. Finally, p.A446S displayed highly variable levels of activity in different tests, in the absence or presence of activators, but in general the values where in the range of the wild type or higher.

Effect of a small intronic deletion on RNA splicing 
The small deletion c.667-14_-7del8 involved intron 5 sequences within the acceptor site, without affecting the conserved AG dinucleotide. Since no RNA was available from patients with this mutation (68a and 68b), a minigene assay was performed to test the effect of this mutation on RNA splicing (Fig. 3A). The genomic region spanning from the $3^{\prime}$ part of intron 3 to the $5^{\prime}$ part of intron 6 of the CBS gene of the mutant and wild-type alleles was PCR-amplified and cloned within intron 7 of a construct containing several GLB1 exons (see Material and Methods for details). Wild-type and mutant constructs were transfected into HeLa cells and splicing was assayed by RT-PCR using the T7 and SP6 primers (Fig. 3B). The major band observed in the wild-type sample corresponds to the inclusion of all three CBS exons, whereas in the mutant, exon 6 was skipped, as assessed by sequencing of all the bands.

\section{Discussion}

Mutation p.T191M was identified in $21.8 \%$ of the alleles of the Spanish and Portuguese patients included in this study (Table 2). Taking into consideration all 50 homocystinuric patients from the Iberian Peninsula included in this and in our previous studies (Urreizti, et al., 2003; 2006a), mutation p.T191M accounts for 44\% of the mutant chromosomes. Mutation c.1566delG is the second most prevalent change (7\% overall), and is particularly common in Portugal (21\%). In the present study, we found the panethnic mutation p.I278T for the first time in two unrelated Spanish patients, both in the heterozygote state, and in a Norwegian patient, in homozygosis (Table 2). Missense mutations are the most common alterations in the CBS gene in the patients of the present study (73\%). We also found six deletions of different sizes (1 bp to 794 bp), five of them novel. 
Southern blot analysis allowed us to identify a large deletion of nearly $800 \mathrm{bp}$ in the heterozygous state (c.532-37_736+438del794, p.V178GfsX23) in patient 87 and in her mother. Additionally, a qmfPCR assay was performed on the patient's sample yielding a consistent result (C. Ged, personal communication). This patient, diagnosed through neonatal screening, presented with dramatically increased plasma methionine $(700 \mu \mathrm{M})$ and total homocysteine $(145 \mu \mathrm{M})$. She has been on a normal diet and treated with pyridoxal, folate and betaine since her birth. Currently aged 4 years, her plasma homocysteine and methionine levels are $76 \mu \mathrm{M}$ and $302 \mu \mathrm{M}$, respectively, and she is clinically asymptomatic, highlighting the importance of an early diagnosis.

An intronic 8-bp deletion (c.667-14_-7del8) was found in two siblings (\#68a\#68b, Table 2). Prediction algorithms indicated a subtle reduction in the score of the splicing acceptor site of intron 5. However, a mini-gene analysis clearly showed that it led to the skipping of exon 6, and produced a frameshift. This is consistent with the severity of the patients' phenotypes. We also found a $5 \mathrm{bp}$ deletion in exon 8 in patient \#109, and a 1 bp deletion in exon 6 in patient \#89, both in homozygosis (Table 2). The severity of these genotypes is in accordance with the severe clinical presentation of both patients. In general, frameshift-generating deletions correlate with a more consistently severe phenotype, as expected.

Seven mutations (six missense and a 3-bp deletion) were expressed in E. coli and analyzed by Western blot under denaturing conditions (Fig. 2, upper panel). Their presence in amounts similar to those of the wild-type CBS suggests that the mutations do not affect protein integrity. Alternatively, they may affect the catalytic core, proper protein folding or the ability to form tetramers. In this regard, several authors have studied the involvement of certain chaperones in the rescue of missense 
CBS mutants, and demonstrated that the regulation of these chaperones could lead to almost complete recovery of the mutant protein activity (Kopecka, et al., 2010; Majtan, et al., 2010; Singh, et al., 2007; Singh, et al., 2010).

Four mutations showed null activity, which supports their pathogenic character. These mutations, p.D281N, p.I278S, p.D321V and p.M173del, were found in four unrelated patients, \#82a (and his siblings), \#94,\#90, and \#55, respectively. No correlation between their null activity and the phenotypes of the patients could be established since all but patient \#94 presented with mild disease.

The other three mutations, displaying different degrees of enzyme activity, were p.P49L, p.P200L and p.A446S, present in patients \#80, \#79 and \#90, respectively, all in the heterozygous state. In these cases, a correlation between their residual activity and the mild phenotype of the patients was observed.

We found the activity of p.P49L to be $75 \%$ of that in the wild type. While our work was ongoing, Kozich et al. (Kozich, et al., 2010) published an analysis of mutation p.P49L expressed in E. coli. They found it to be an active enzyme, indistinguishable from the wild type. Mutation p.P49L was found in two siblings, one with adult onset and the other asymptomatic. Genetic analysis of the proband (\#80a in Table 2 and subject II.1 in Fig. 4), showed compound heterozygosity for p.P49L and p.R125Q (Table 2). Genotyping of his siblings revealed an asymptomatic sister also carrying both mutations (\#80b; II.3 in Fig. 4). The proband had suffered a myocardial infarction at age 53. Blood testing revealed moderate hyperhomocysteinemia and hypermethioninemia (58 and $655 \mu \mathrm{M}$, respectively) and he responded well to PLP (tHcy: $28 \mu \mathrm{M}$ after treatment). On the other hand, his asymptomatic sister, aged 54, presented with severe hyperhomocysteinemia (543 $\mu \mathrm{M})$ and hypermethioninemia $(1723 \mu \mathrm{M})$ but had no clinical sign of classical 
homocystinuria and had given birth to three healthy offspring without complications. As the two CBS mutations were inherited separately by the offspring, we know that they were not in cis in the mother or in his affected brother. Mutation p.R125Q, the other mutation in family \#80, was originally described as a null activity mutation (Sebastio, et al., 1995). In their recent publications, Kozich et al. (Kozich, et al., 2010) and Majtan et al. (Majtan, et al., 2010) expressed it in E. coli. In both studies the reduced activity was improved under permissive conditions or in the presence of chaperones. Taken together, these new results on p.P49L and p.R125Q help explain the mild or null affectation of patients \#80a and \#80b. In addition, the MTHFR $677 \mathrm{C}>\mathrm{T}$ polymorphism may act as a phenotype modifier in this family. However, the discrepancy between the blood markers and the phenotype of patient \#80b remains unexplained.

Mutation p.P200L was identified as the sole mutation in patient \#79. The patient's symptoms are limited to hypertension and severe hyperhomocysteinemia $(183 \mu \mathrm{M})$, which does not respond to vitamin B6 and folate treatment. A second CBS mutation may be deep intronic, located in a regulatory region far from the gene, or involved in a complex rearrangement not detected by our screening methods. Mutation p.A446S was found in a mildly affected patient (\#90, Table 2), in compound heterozygosis with the null mutation p.D321V (Fig. 2). The activity of p.A446S was very similar to that of the wild type and this correlates with the mild phenotype of the patient, who only presented with lens dislocation at 45 years, despite a high tHcy level $(105 \mu \mathrm{M}$, which was reduced to $40 \mu \mathrm{M}$ after two months of treatment with folic acid and vitamins B6 and B12).

The poor genotype-phenotype correlation widely observed by us and others among the homocystinuric patients and the demonstration that some patients 
carrying two CBS mutant alleles are asymptomatic, call for environmental and genetic modifiers involved in the pathophysiology of the disease. Some of these genetic factors may be involved in the folding and degradation of the mutant proteins.

\section{Acknowledgements}

The authors are grateful to the patients and their families. We also thank the following colleagues for providing samples and clinical data: A.Baldellou and M.T.Calvo (Zaragoza), M.T.García-Silva and M.Pardo (Madrid), M.Urtasun (San Sebastian), O.Alonso (Huelva), A.Reparaz and C.Torreira (Vigo), I.C.Verma (New Delhi, India). Robin Rycroft revised the English. The CIBER de Enfermedades Raras (CIBERER) is an initiative of the ISCIII. This study was supported by grants from Ministerio de Ciencia e Innovación (Grants SAF2007-64654; SAF2010-15707; PIB2010AR-00473), and the Catalan Department of Universities, Research and the Information Society (2005SGR 00848, 2009 SGR 971).

\section{References:}

Banerjee R, Zou C. 2005. Redox regulation and reaction mechanism of human cystathionine$\beta$-synthase: a PLP-dependent hemesensor protein. Arch Biochem Biophys 433:144156.

Bukovska G, Kery V, Kraus JP. 1994. Expression of human cystathionine beta-synthase in Escherichia coli: purification and characterization. Protein Expr Purif 5:442-8.

Chen X, Wang L, Fazlieva R, Kruger WD. 2006. Contrasting behaviors of mutant cystathionine beta-synthase enzymes associated with pyridoxine response. Hum Mutat 27:474-82.

de Franchis R, Kozich V, Mclinnes RR, Kraus JP. 1994. Identical genotipes in siblings with differnt homocystinuric phenotypes: identification of three mutations in cystationine B-synthase usin en improved bacterial expression system. Hum Mol Genet 3:11031108.

de Franchis R, Sperandeo MP, Sebastio G, Andria G. 1998. Clinical aspects of cystathionine beta-synthase deficiency: how wide is the spectrum? The Italian Collaborative Study Group on Homocystinuria. Eur J Pediatr 157 Suppl 2:S67-70.

Diaz-Font A, Santamaria R, Cozar M, Blanco M, Chamoles N, Coll MJ, Chabas A, Vilageliu L, Grinberg D. 2005. Clinical and mutational characterization of three patients with 
multiple sulfatase deficiency: report of a new splicing mutation. Mol Genet Metab 86:206-11.

El-Said MF, Badii R, Bessisso MS, Shahbek N, El-Ali MG, El-Marikhie M, El-Zyoid M, Salem MS, Bener A, Hoffmann GF and others. 2006. A common mutation in the CBS gene explains a high incidence of homocystinuria in the Qatari population. Hum Mutat 27:719.

Frosst P, Blom HJ, Milos R, Goyette P, Sheppard CA, Matthews RG, Boers GJ, den HM, Kluijtmans LA, van dHL and others. 1995. A candidate genetic risk factor for vascular disease: a common mutation in methylenetetrahydrofolate reductase [letter]. Nat Genet 10:111-3.

Gallagher PM, Ward P, Tan S, Naughten E, Kraus JP, Sellar GC, McConnell DJ, Graham I, Whitehead AS. 1995. High frequency (71\%) of Cystathionine B-Synthase Mutation G307S in Irish Homocystinuria Patients. Hum Mutat 6:177-180.

Gaustadnes M, Ingerslev J, Rutiger N. 1999. Prevalence of congenital homocystinuria in Denmark. N Engl J Med 340:1513.

Janosik M, Meier M, Kery V, Oliveriusova J, Burkhard P, Kraus JP. 2001a. Crystallization and preliminary $\mathrm{X}$-ray diffraction analysis of the active core of human recombinant cystathionine beta-synthase: an enzyme involved in vascular disease. Acta Crystallogr D Biol Crystallogr 57:289-91.

Janosik M, Oliveriusova J, Janosikova B, Sokolova J, Kraus E, Kraus JP, Kozich V. 2001b. Impaired heme binding and aggregation of mutant cystathionine beta-synthase subunits in homocystinuria. Am J Hum Genet 68:1506-1513.

Kabil O, Toaka S, LoBrutto R, Shoemaker R, Banerjee R. 2001. Pyridoxal phosphate binding sites are similar in human heme-dependent and yeast heme-independent cystathionine beta-synthases. Evidence from 31P NMR and pulsed EPR spectroscopy that heme and PLP cofactors are not proximal in the human enzyme. J Biol Chem 276:19350-5.

Katsushima F, Oliveriusova J, Sakamoto O, Ohura T, Kondo Y, Iinuma K, Kraus E, Stouracova R, Kraus JP. 2006. Expression study of mutant cystathionine beta-synthase found in Japanese patients with homocystinuria. Mol Genet Metab 87:323-8.

Kery V, Poneleit L, Meyer JD, Manning MC, Kraus JP. 1999. Binding of pyridoxal 5phosphate to the heme protein human cystathionine beta-synthase. Biochemistry 38:2716-2724.

Kluijtmans LA, Boers GH, Stevens EM, Renier WO, Kraus JP, Trijbels FJ, van den Heuvel LPWJ, Blom HJ. 1996. Defective Cystathionine B-synthase regulation by SAdenosylmethionine in a partially pyridoxine responsive homocystinuria patient. $\mathrm{J}$ Clin Invest 98:285-289.

Kopecka J, Krijt J, Rakova K, Kozich V. 2011. Restoring assembly and activity of cystathionine beta-synthase mutants by ligands and chemical chaperones. J Inherit Metab Dis. 34:39-48.

Kozich V, Kraus JP. 1992. Screening for mutations by expressing patient cDNA segments in E. coli: Homocystinuria due to Cystathionine $\beta$-Synthase Deficiency. Hum Mutat 1:113-123.

Kozich V, Sokolova J, Klatovska V, Krijt J, Janosik M, Jelinek K, Kraus JP. 2010. Cystathionine beta-synthase mutations: effect of mutation topology on folding and activity. Hum Mutat 31:809-19.

Kraus J. 1987. Cystathionine b-synthase. Methods in enzymology 143:388-394.

Kraus J, Janosik M, Kozich V, Mandell R, Shih V, Sperandeo MP, Sebastio G, de Franchis R, Andria G, Kluijtmans LAJ and others. 1999. Cystathionine beta-synthase mutations in homocystinuria. Hum Mutat 13:362-375. 
Maclean KN, Gaustadnes M, Oliveriusova J, Janosik M, Kraus E, Kozich V, Kery V, Skovby F, Rudiger N, Ingerslev J and others. 2002. High homocysteine and thrombosis without connective tissue disorders are associated with a novel class of cystathionine beta-synthase (CBS) mutations. Hum Mutat 19:641-655.

Magner M, Krupkova L, Honzik T, Zeman J, Hyanek J, Kozich V. 2011. Vascular presentation of cystathionine beta-synthase deficiency in adulthood. J Inherit Metab Dis 34:33-7.

Majtan T, Liu L, Carpenter JF, Kraus JP. 2010. Rescue of cystathionine beta-synthase (CBS) mutants with chemical chaperones: purification and characterization of eight CBS mutant enzymes. J Biol Chem. 285:15866-15873.

Meier M, Janosik M, Kery V, Kraus JP, Burkhard P. 2001. Structure of human cystathionine beta-synthase: a unique pyridoxal 5 '-phosphate-dependent heme protein. EMBO J 20:3910-3916.

Moat SJ, Bao L, Fowler B, Bonham JR, Walter JH, Kraus JP. 2004. The molecular basis of cystathionine beta-synthase (CBS) deficiency in UK and US patients with homocystinuria. Hum Mutat 23:206.

Mudd S, Levy H, Tangerman A, Boujet C BN, Davidson-Mundt A, Hudgins L, Oyanagi K, Nagao M, Wilson W. 1995. Isolated persistent hypermethioninemia. Am J Hum Genet 57:882-92.

Mudd SH, Skovby F, Levy HL, Pettigrew KD, Wilcken B, Pyeritz RE, Andria G, Boers GH, Bromberg IL, Cerone R and others. 1985. The natural history of homocystinuria due to cystathionine beta-synthase deficiency. Am J Hum Genet 37:1-31.

Refsum H, Fredriksen A, Meyer K, Ueland PM, Kase BF. 2004. Birth prevalence of homocystinuria. J Paediatr 144:830-832.

Santamaria R, Vilageliu L, Grinberg D. 2008. SR proteins and the nonsense-mediated decay mechanism are involved in human GLB1 gene alternative splicing. BMC Res Notes $1: 137$.

Sebastio G, Sperandeo MP, Panico M, de Franchis R, Kraus JP, Andria G. 1995. The molecular basis of homocystinuria due to Cystathionina B-Sinthasa deficiency in italian families, and report of four novel mutations. Am J Hum Genet 56:1324-1333.

Singh LR, Chen X, Kozich V, Kruger WD. 2007. Chemical chaperone rescue of mutant human cystathionine beta-synthase. Mol Genet Metab 91:335-42.

Singh LR, Gupta S, Honig NH, Kraus JP, Kruger WD. 2010. Activation of mutant enzyme function in vivo by proteasome inhibitors and treatments that induce Hsp70. PLoS Genet 6:e1000807.

Skovby F, Gaustadnes M, Mudd SH. 2010. A revisit to the natural history of homocystinuria due to cystathionine beta-synthase deficiency. Mol Genet Metab 99:1-3.

Taoka S, Lepore BW, Kabil O, Ojha S, Ringe D, Banerjee R. 2002. Human cystathionine beta-synthase is a heme sensor protein. evidence that the redox sensor is heme and not the vicinal cysteines in the CXXC motif seen in the crystal structure of the truncated enzyme. Biochemistry 41:10454-10461.

Urreizti R, Asteggiano C, Bermudez M, Cordoba A, Szlago M, Grosso C, de Kremer RD, Vilarinho L, D'Almeida V, Martinez-Pardo M and others. 2006a. The p.T191M mutation of the CBS gene is highly prevalent among homocystinuric patients from Spain, Portugal and South America. J Hum Genet 51:305-13.

Urreizti R, Asteggiano C, Cozar M, Frank N, Vilaseca MA, Grinberg D, Balcells S. 2006b. Functional assays testing pathogenicity of 14 cystathionine-beta synthase mutations. Hum Mutat 27:211.

Urreizti R, Balcells S, Rodes M, Vilarinho L, Baldellou A, Couce ML, Munoz C, Campistol J, Pinto X, Vilaseca MA and others. 2003. Spectrum of CBS mutations in 16 


\section{Figure Legends:}

Figure 1. Southern Blot analysis of the CBS gene. A: scheme of the human $C B S$ gene. The DrdI (D) and AflII (A) restriction sites and the corresponding restriction fragments (F1 to F4) are indicated below the scheme. The positions of the probes (A to D) are indicated above. B: Southern Blot analysis of patient \#87 and her mother (\#87m) hybridized with the whole set of probes. Two wild-type DNAs were included in the analysis. M: Molecular weight marker. C: Southern Blot analysis hybridized with probe $\mathrm{B}$. The arrow indicates the new band found in the patient and her mother. D: PCR amplification of the fragment from intron 3 to intron 7. An extra band of reduced size was found in patient 87 and her mother, corresponding to a 794-bp deletion. The asterisk indicates the heteroduplex. E: Chromatogram of patient 87 showing the deletion boundaries.

Figure 2. Heterologous expression and activity of seven CBS mutations. A: SDSPAGE followed by Western blot immunodetection of wild-type and mutant CBS 
proteins expressed in E. coli XL Gold. Ten $\mu$ g of total protein extract was loaded in each lane. Six replicates were performed for each mutation. pKK: Empty vector used as negative control. B: In vitro enzyme activity of wild-type and mutant CBS alleles from E. coli XL Gold extracts in the absence of both PLP and SAM (black boxes), in the presence of PLP (grey boxes), and in the presence of both PLP and SAM (white boxes). Wild-type CBS activity in the presence of PLP was taken as the reference value (100\%). Activity values greater than $4 \%$ are indicated in the figure. Values are the means of six replicates. Error bars represent SD.

Figure 3. Splicing analysis of mutation c.667-14_-7del8 included in a minigene construction. A: scheme of the minigene: grey boxes represent GLB1 exons and white boxes are $C B S$ exons. The thick horizontal line represents the $C B S$ introns and the thin line the GLB1 introns. PCMV: CMV promoter; BGHpA: BGH polyadenylation site. Wild-type and mutant splicing patterns are indicated above and below the gene respectively. The dot indicates the position of the mutation. The wild-type and mutant constructs were transiently transfected into HeLa cells. Total RNA was extracted $24 \mathrm{~h}$ after transfection, reverse-transcribed and PCR-amplified with primers T7 and SP6 (indicated by arrows). B: PCR amplification of the wild-type (1) mutant (2) and the minigene construct without the CBS exons (3). The asterisk points to a minor band lacking exon 4 observed in the wild-type construct. C: Diagrams showing the three main PCR products.

Figure 4. Pedigree of family 80. Patient 80a (II.1), the proband, is marked with an arrow. Patient $80 \mathrm{~b}$ is member II.3. CBS genotypes are indicated below the pedigree symbols; the MTHFR c.677C>T genotypes are also included in brackets. Total plasma homocysteine levels $(\mu \mathrm{Mol} / \mathrm{L})$ are indicated when available. NA: not available. 
Table 1. List Of The 22 Different Mutations Found In This Cohort.

\begin{tabular}{|c|c|c|c|c|c|}
\hline DNA & $\begin{array}{c}\text { Deduced } \\
\text { Protein Change }\end{array}$ & $\begin{array}{l}\text { Exon- } \\
\text { Intron }\end{array}$ & Alleles & $\begin{array}{l}\text { Restr. } \\
\text { Enz. }^{1}\end{array}$ & References \\
\hline c. $146 \mathrm{C}>\mathrm{T}$ & p.P49L & Ex 1 & 1 & & de Franchis et al., 1998 \\
\hline c. $253 \mathrm{G}>\mathrm{A}$ & p.G85R & Ex 2 & 1 & & Maclean et al., 2002 \\
\hline c. $361 \mathrm{C}>\mathrm{T}$ & p.R121C & Ex 3 & 1 & & Katsushima et al., 2006 \\
\hline c. $374 \mathrm{G}>\mathrm{A}$ & p.R125Q & Ex 3 & 1 & & Marble et al., 1994 \\
\hline c.518delTGA & p.M173del & Ex 4 & 2 & & This study \\
\hline c.532-37_736+438del794 & p.V178GfsX23 & In 4-In 6 & 1 & & This study \\
\hline c. $572 \mathrm{C}>\mathrm{T}$ & p.T191M & Ex 5 & 7 & & Urreizti et al., 2003 \\
\hline c.599C $>\mathrm{T}$ & p.P200L & Ex 5 & 1 & MspI- & This study \\
\hline c.667-14_667-7del8 & p.Y223GfsX23 & In 5 & $\mathbf{1}$ & & This study \\
\hline c. $676 \mathrm{G}>\mathrm{A}$ & p.A226T & Ex 6 & 2 & & Shan et al., 1998 \\
\hline c.689delT & p.L230RfsX39 & Ex 6 & 1 & MspI+ & This study \\
\hline c. $824 \mathrm{G}>\mathrm{A}$ & p.C275Y & Ex 7 & 1 & & Urreizti et al., 2003 \\
\hline c.833T $>$ G & p.I278S & Ex 8 & 1 & TspRi+ & This study \\
\hline c. $833 \mathrm{~T}>\mathrm{C}$ & p.I278T & Ex 8 & 4 & & Kozich et al., 1992 \\
\hline c.841C $>\mathrm{T}$ & p.D281N & Ex 8 & 1 & BamHI- & This study \\
\hline c.862_866del5 & p.E289GfsX39 & Ex 8 & 2 & & This study \\
\hline c.962A $>\mathrm{T}$ & p.D321V & Ex 9 & 1 & Нру8I- & This study \\
\hline c. $1085 \mathrm{C}>\mathrm{T}$ & p.T353M & Ex 10 & 2 & & Dawson et al., 1997 \\
\hline c. $1136 \mathrm{G}>\mathrm{A}$ & p.R379Q & Ex 10 & 1 & & Urreizti et al., 2003 \\
\hline c. $1330 \mathrm{G}>\mathrm{A}$ & p.D444N & Ex 12 & 4 & & Kluijtmans et al., 1996 \\
\hline c. $1336 G>T$ & p.A446S & Ex 12 & 1 & $B s t \mathrm{NI}+$ & This study \\
\hline c.1566delG & p.K523SfsX18 & Ex 16 & 5 & & Castro et al., 1999 \\
\hline
\end{tabular}

Mutations not previously described are indicated in bold

${ }^{\mathbf{1}}$ Novel missense mutations were checked in control chromosomes using the indicated enzyme. + : the mutation creates a new site; -: the mutation destroys a site.

Reference Sequences: Genomic, GenBank NG_008938.1; cDNA, ENST00000352178. Nucleotide numbering reflects cDNA numbering with +1 corresponding to the A of the ATG translation initiation codon in the reference sequence, according to journal guidelines (www.hgvs.org/mutnomen). The initiation codon is codon 1 . 
Table 2. Patients, CBS And MTHFR C.667C>T Genotypes, Disease Severity And Geographical Origin

\begin{tabular}{|c|c|c|c|c|}
\hline Patient & Genotype & $\begin{array}{c}\text { MTHF } \\
\text { R } \\
(\mathbf{c . 6 7 7} \\
\text { C>T) }\end{array}$ & Severity & Country \\
\hline 74 & p.[T353M]+[D444N] & TT & Severe & Spain \\
\hline 79 & p. $[\mathbf{P 2 0 0 L}]+[?]$ & CT & Asymptomatic & Spain \\
\hline $80 \mathrm{a}$ & $\mathrm{p} .[\mathrm{R} 125 \mathrm{Q}]+[\mathrm{P} 49 \mathrm{~L}]$ & TT & Mild & Spain \\
\hline $80 \mathrm{~b}$ & $\mathrm{p} .[\mathrm{R} 125 \mathrm{Q}]+[\mathrm{P} 49 \mathrm{~L}]$ & $\mathrm{CT}$ & Asymptomatic & \\
\hline $82 \mathrm{a}$ & p. $[\mathrm{T} 191 \mathrm{M}]+[\mathbf{D} 281 \mathbf{N}]$ & $\mathrm{CC}$ & Mild & Spain \\
\hline $82 b$ & p. $[\mathrm{T} 191 \mathrm{M}]+[\mathbf{D} 281 \mathrm{~N}]$ & $\mathrm{CC}$ & Mild & \\
\hline $82 c$ & p. $[\mathrm{T} 191 \mathrm{M}]+[\mathbf{D} 281 \mathbf{N}]$ & $\mathrm{CC}$ & Mild & \\
\hline 83 & $\mathrm{p} .[\mathrm{T} 353 \mathrm{M}]+[\mathrm{D} 444 \mathrm{~N}]$ & TT & Mild & Spain \\
\hline 84 & p. $[\mathrm{I} 278 \mathrm{~T}]+[\mathrm{R} 121 \mathrm{C}]$ & $\mathrm{CT}$ & Mild & Spain \\
\hline 88 & p. $[\mathrm{D} 444 \mathrm{~N}]+[\mathrm{D} 444 \mathrm{~N}]$ & $\mathrm{CT}$ & Mild & Spain \\
\hline 92 & p. $[\mathrm{T} 191 \mathrm{M}]+[\mathrm{T} 191 \mathrm{M}]$ & $\mathrm{CT}$ & Mild & Spain \\
\hline 93 & p. $[\mathrm{T} 191 \mathrm{M}]+[\mathrm{T} 191 \mathrm{M}]$ & $\mathrm{CT}$ & Severe & Spain \\
\hline 94 & p. $[\mathrm{T} 191 \mathrm{M}]+[\mathbf{I 2 7 8 S}]$ & $\mathrm{CT}$ & Severe & Spain \\
\hline 100 & p. $[\mathrm{T} 191 \mathrm{M}]+[\mathrm{R} 379 \mathrm{Q}]$ & $\mathrm{CT}$ & Mild & Spain \\
\hline 107 & c. $[1566 \mathrm{delG}]+[1566 \mathrm{delG}]$ & CT & NA & Spain \\
\hline 108 & p. $[\mathrm{I} 278 \mathrm{~T}]+[\mathrm{C} 275 \mathrm{Y}]$ & TT & Mild & Spain \\
\hline 81 & c. $[1566 \mathrm{delG}]+[1566 \mathrm{delG}]$ & TT & Severe & Portugal \\
\hline 87 & c. $[1566 \mathrm{delG}]+\left[532-37 \_736+438 d e l 794\right]$ & $\mathrm{CC}$ & $\begin{array}{c}\text { neonatal screening } \\
\text { (asymptomatic) }\end{array}$ & Portugal \\
\hline 109 & p.[E289GfsX39]+[E289GfsX39] & CT & Severe & Portugal \\
\hline $68 \mathrm{a}$ & p.[G85R]+c.[667-14_667-7del8] & $\mathrm{CT}$ & Severe & Argentina \\
\hline $68 b$ & p.[G85R]+c.[667-14_667-7del8] & CT & Severe & \\
\hline 89 & c. $[689$ delT $]+[689$ delT $]$ & $\mathrm{CT}$ & Severe & Argentina \\
\hline 90 & p. $[\mathrm{D321V}]+[\mathrm{A446S}]$ & $\mathrm{CT}$ & Mild & Argentina \\
\hline 91 & p. $[\mathrm{A} 226 \mathrm{~T}]+[\mathrm{A} 226 \mathrm{~T}]$ & $\mathrm{CT}$ & Severe & Argentina \\
\hline 105 & p. $[\mathrm{I} 278 \mathrm{~T}]+[\mathrm{I} 278 \mathrm{~T}]$ & ND & NA & Norway \\
\hline 55 & p. $[$ M173del $]+[$ M173del $]$ & ND & Mild & Indian \\
\hline
\end{tabular}

ND: Not Determined.

NA: Not Available. 


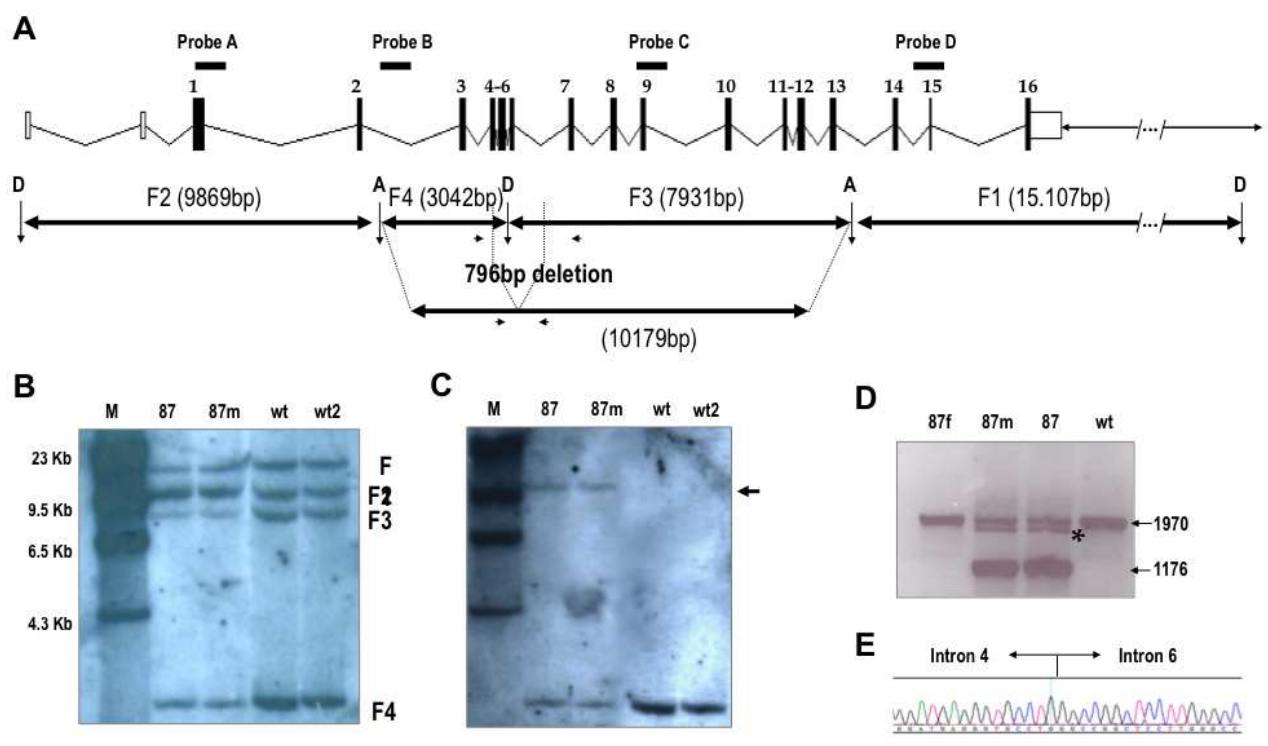

$355 \times 266 \mathrm{~mm}(72 \times 72$ DPI $)$

John Wiley \& Sons, Inc. 


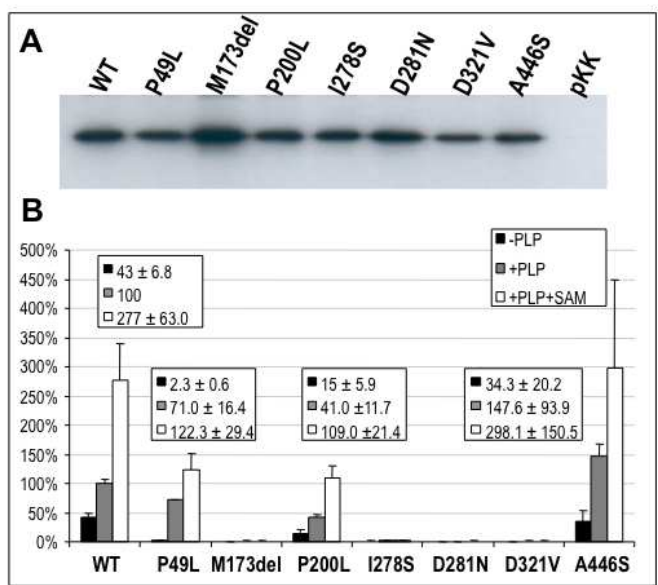

$355 \times 266 \mathrm{~mm}(72 \times 72$ DPI $)$

John Wiley \& Sons, Inc. 

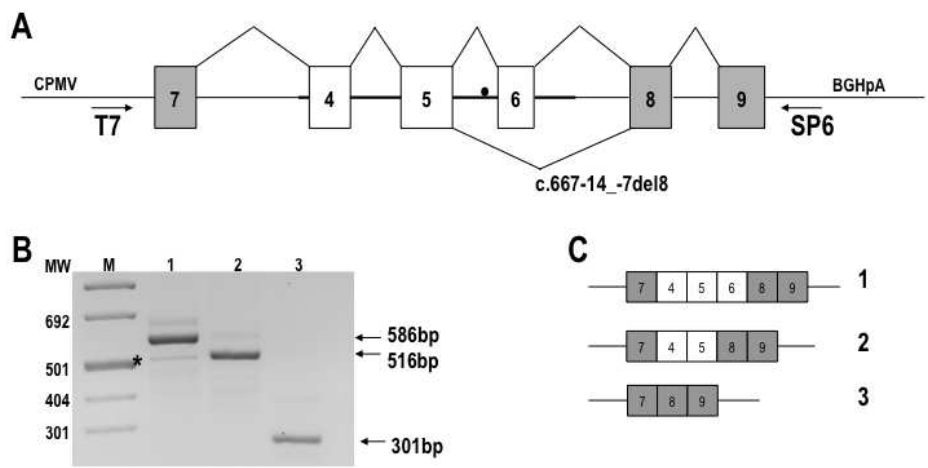

$355 \times 266 \mathrm{~mm}(72 \times 72$ DPI $)$

John Wiley \& Sons, Inc. 


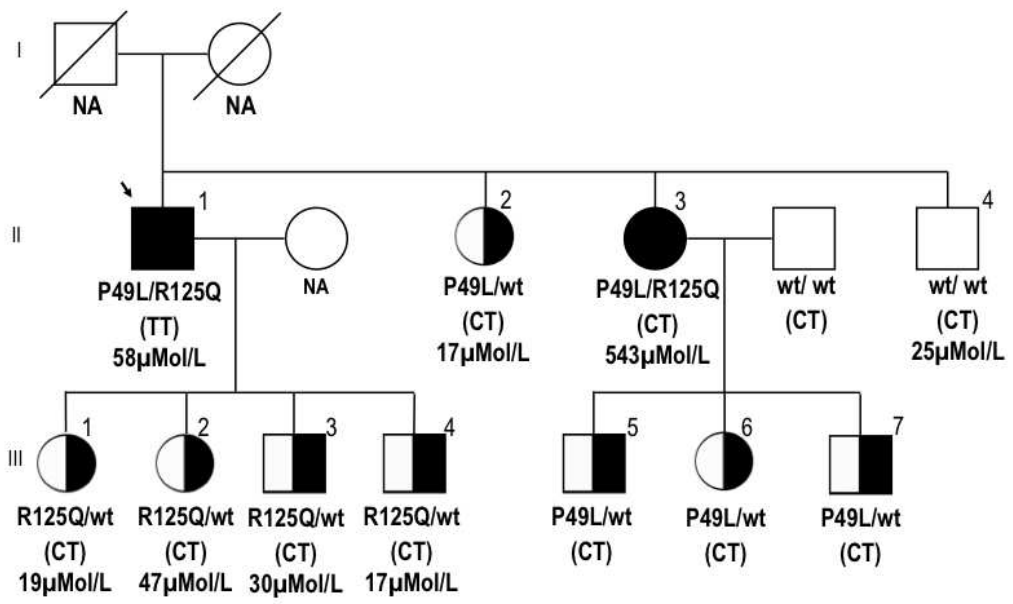

